\title{
EFFECT OF FLAP AND FLAPLESS PROCEDURES IN DENTAL IMPLANT INSTALLATION ON INITIAL CRESTAL BONE LOSS
}

\author{
Mohamed Ahmed Deabs*, Mahmoud Ahmed Abdallah**, Mohammad Abdel-hamied Shuman ${ }^{* * *}$
}

\begin{abstract}
Objective: The present study was designed to evaluate the effect of flap and flapless procedures in dental implant installation on initial crestal bone loss. Subjects \& Methods: Twelve patients were enrolled in the present study. These patients were divided into two groups. In group I (flapless group), implants were inserted without elevation of a mucoperiosteal flap. In group II (flap group), implants were inserted through elevation of a mucoperiosteal flap. Patients were followed up at the $2^{\text {nd }}$ and $7^{\text {th }}$ days after surgery for severity of pain, swelling, infection, dehiscence of the tissue. The periodontal probing depth, post-operative implant stability, crestal bone level, and postoperative bone density were measured 6 months after surgery. Results: The flapless technique group showed statistically significant reduction in pain intensity and swelling than the flap technique. Patients operated with flap technique showed higher pocket depth than patients operated with flapless technique. The implant stability was greater in patients of flapless group than in patients of flap group. The amount of crestal bone loss was less in the flapless group than the flap group. Bone density was increased in the flapless group as well as in the flap group. Conclusion: Both techniques achieved good success rates, and the flapless technique showed no advantage over flap technique regarding probing depth, implant stability and bone density. Moreover, the use of flapless technique might produce less postoperative soft tissue inflammation, pain and significant reduction in the amount of crestal bone loss compared to flap technique.
\end{abstract}

Key words: dental implant, crestal bone loss, flapless procedure.

\section{INTRODUCTION}

Dental implants serve as artificial tooth roots and have been successful in preventing the physical and cosmetic associated with tooth loss. The longterm survival of dental implants is evaluated by the amount of crestal bone loss around the implant. Within the first year after implant insertion an increased amount of peri-implant bone resorption has been observed ${ }^{(1)}$.

The cause of the increased initial bone loss within the first year after insertion is not fully understood. However, based on data available to date, there is evidence that factors influence crestal bone loss might be implant design; implant surface, insertion depth, platform switching, postsurgical manipulation, micro-gaps between the implant and abutment and stability of the implant-abutment connection, overload by occlusal force or periimplantitis ${ }^{(2)}$.

Implant placement could be achieved through direct exposure of the alveolar ridge using a full thickness mucoperiosteal flap or through a flapless procedure. The effect of the surgical trauma caused by raising a mucoperiosteal flap is a subject for scientific investigation. It has been found that the dental implants that were placed after reflecting flap show some bone resorption during the initial phase of healing almost at the crestal region ${ }^{(3)}$.

\footnotetext{
* Masters Candidate

** Professor, Department of Oral and Maxillofacial Surgery, Faculty of Dental Medicine, Boys, Cairo Al-Azhar University

*** Assistant Professor, Oral and Maxillofacial Surgery Faculty of Dental Medicine,Assiut Al-Azhar University
} 
In flapless procedure, a dental implant is installed through the mucosal tissues without reflecting a flap. This approach has advantage for soft tissue healing and patient comfort because it is less traumatic, less time consuming with less postoperative bleeding and swelling ${ }^{(4)}$. It is assumed that flapless procedure for dental implant installation may decrease initial bone loss. The aim of the research was directed to evaluate this statement.

\section{SUBJECTS AND METHODS}

Twelve patients were enrolled in the study (5 males and 7 females) with their ages ranged from 18 to 60 years.

Inclusion Criteria: Patients with posterior missing teeth in both jaws, male or female patients with an age ranged between 18 to 50 years old, patients with adequate alveolar ridge bone height, width, the length and width of the site should be adequate to accommodate an appropriately sized implant, and enough attached gingival keratinized tissue at least $2 \mathrm{~mm}$ to support an adequate attached tissue cuff around the implant.

Exclusion Criteria: Extraction socket less than 4 months of healing time, heavy smoker, alcohol and drug abuse, patient with history of uncontrolled diabetes, patients with history of radiotherapy or chemotherapy, patients with history of bruxism, and history of long-term medication affecting on periodontal tissue such as nonsteroidal antiinflammatory drug, cyclosporine, glucocorticoids. Lactating or pregnant females.

The patients were randomly divided into two groups of 6 patients each. In group I (flapless group), implants were inserted without elevation of a mucoperiosteal flap guided by custom made surgical stent. In group II (flap group), implants were inserted through elevation of a mucoperiosteal flap. After implant installation, intraoperative primary implant stability was measured. Patients were followed up at the $2^{\text {nd }}$ and $7^{\text {th }}$ days after surgery for severity of pain, swelling, infection, dehiscence of the tissue. The periodontal probing depth was measured at abutment placement and after three months from crown cementation. Postoperative implant stability was measured 6 months after surgery. Crestal bone level was measured with the aid of cone beam computed tomography (CBCT) immediately after surgery and after 6 months. Postoperative measurement of bone density was performed 6 months after surgery. The preoperative and postoperative readings were collected and subjected for statistical comparisons.

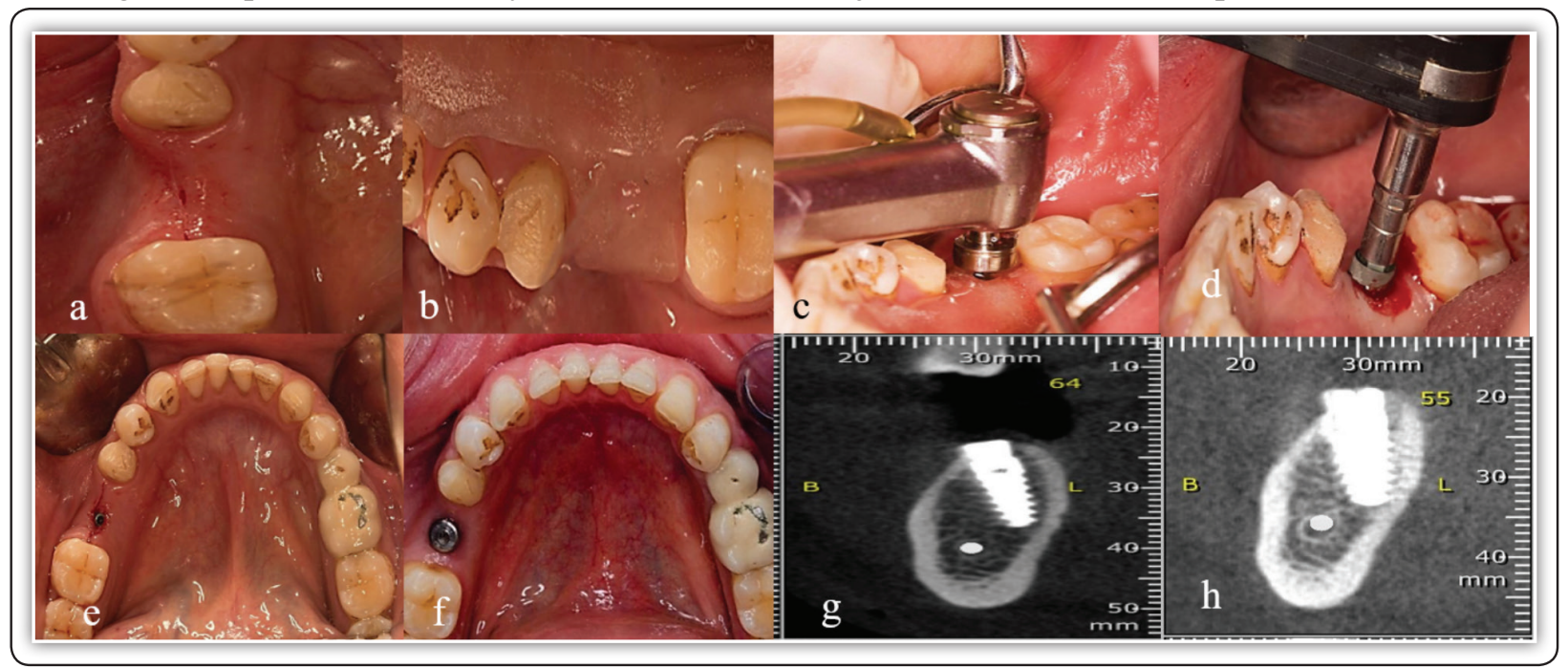

FIG (1) a; Small crestal incision in group I, b; Custom made surgical stent in place in group I, c; Drilling guided by custom made surgical stent in group I, d; A ratchet wrench was used to insert the implant to the final insertion depth in group I, completely insertion implant in group I, f; The implant will be connected to healing abutment in group I, g; Immediate postoperative $\mathrm{CBCT}$ and $\mathbf{h}$; Postoperative $\mathrm{CBCT}$ after 6 months. 


\section{RESULTS}

The flapless technique group showed statistically significant reduction in pain intensity and swelling than the flap technique. Patients operated with flap technique showed higher pocket depth than patients operated with flapless technique. However, the difference between both groups was non-significant. The implant stability was greater in patients of flapless group than in patients of flap group. However, the difference between both groups was statistically non-significant. The amount of crestal bone loss was less in the flapless group than the flap group. The difference was statistically significant. Bone density was increased in the flapless group as well as in the flap group. Statistically, the difference between both groups was non-significant.

TABLE (1): Comparison between the two studied groups according to mean Probing depth, Implant stability, Crestal bone loss and Bone density.

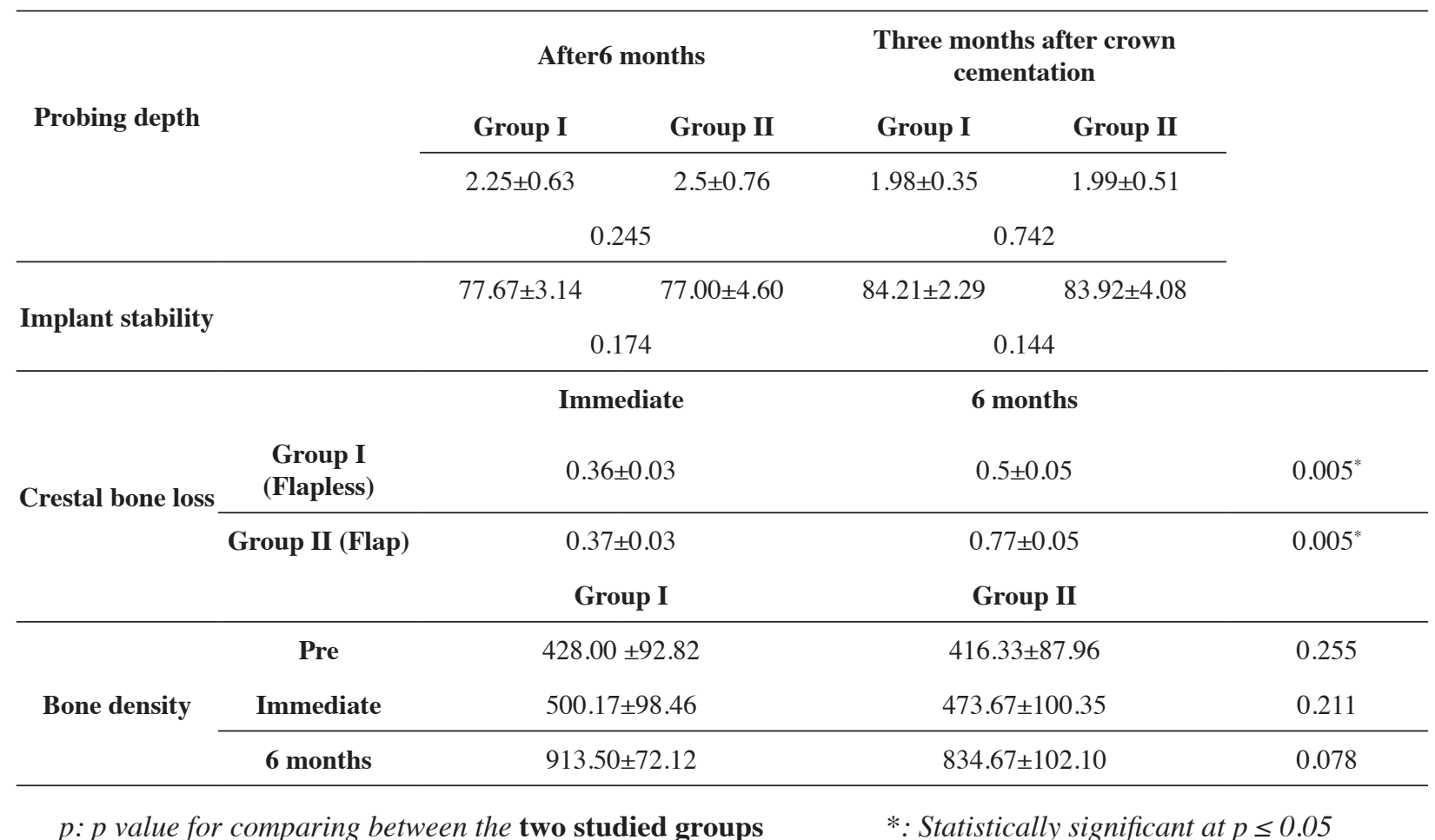

\section{DISCUSSION}

Neither flapless nor flap techniques resulted in dehiscence. Dehiscence is opening of the surgical wound edges exposing part or all of the implant head and/or surrounding bony tissues ${ }^{(5)}$. A lot of factors aid in absence of dehiscence in the present study; the mucosa was of normal thickness, success to ensure passive re-approximation and closure of the flap margins without insufficient or excessive tension on the suture and absence of large edema or hematoma ${ }^{(6)}$.

It has been stated that successful implants generally allow probe penetration of approximately $3 \mathrm{~mm}$ after implant loading measured from the crown margin to the base of the sulcus using a plastic periodontal prob. Pockets of $5 \mathrm{~mm}$ or greater 
can be viewed as protected habitats for putative periodontal pathogens and are a sign of periimplantitis ${ }^{(7)}$.

Pocket depths around sites of all implants were recorded at defined intervals in this study and all pocket depths around the implants were less than $3 \mathrm{~mm}$ and remained stable throughout the investigation. Patients operated with flap technique showed higher pocket depth than patients operated with flapless technique. However, the difference between both groups was non-significant. This agrees with Wang et al ${ }^{(8)}$ who found no significant difference in pocket depth at every appointment between the flap and flapless group. On the other hand, Jiao and $\mathrm{Gao}^{\left({ }^{(9)}\right.}$ and Anumala et al ${ }^{(10)}$ found that flapless technique had significantly reduced pocket depth and better soft tissue changes was achieved than flap technique.

Achievement and maintenance of implant stability are prerequisites for successful clinical outcome, therefore; measuring the implant stability is an important method for evaluating the success of an implant. Implant stability is achieved at two different stages: primary and secondary. Primary stability of an implant comes from mechanical engagement with cortical bone. It is affected by bone quantity and quality, surgical procedure, length, diameter, and form of implant. Secondary stability is developed from regeneration and remodeling of the bone and tissue around the implant after insertion but is affected by the primary stability, bone formation and remodeling ${ }^{(11)}$.

The time of functional loading is dependent upon the secondary stability. An adequate stability of the dental implant in the surrounding bone plays an important role in the bone healing processes, avoiding micro movement and damage to the bone healing process. It is, therefore, of an utmost importance to be able to quantify implant stability at various time points and to project a long-term prognosis based upon measured implant stability. Presently, various diagnostic analyses have been suggested to define implant stability as the implant insertion torque at the moment of placement and osstell. When using osstell mentor, the smart peg must maintain a distant of approximately $1-3 \mathrm{~mm}$, angle of 90 degrees, $3 \mathrm{~mm}$ above the soft tissue and otherwise the measured value may be affected ${ }^{(12)}$.

Regarding stability, there was increase of ISQ values from the base line reading to the 6 months reading in both groups. The ISQ value was greater in patients of flap less group than in patients of flap group. However, the difference between both groups was not statistically significant. This is because in the weeks following the placement of an endosseous implant, primary mechanical implant stability is gradually replaced by biological stability. When soft tissue flaps are reflected for implant placement, the blood supply from the soft tissue to the bone is also removed, leaving only poorly vascularized cortical bone. The preservation of bone vascularization through use of the flapless technique may help to optimize bone regeneration around implants, while full-thickness flaps demonstrate high bone resorption after surgery ${ }^{(13)}$.

The long-term survival of dental implants is evaluated by the amount of crestal bone loss around the implant. The peri implant crestal bone level and peri implant bone remodeling depends upon location of implant abutment junction in relation to bone crest and the amount of soft tissue coverage. We must be fully aware of the resorption that crestal bone experiences after surgical procedures involving incision with flap elevation. This occurs unpredictably, as a result of the alteration in the vascularization of the bone periosteum after flap reflection. Several experimental studies verified that avoid flap reflection on the insertion of dental implants prevents the alteration of the vascularization of the area, improving the behavior of mucosa, periosteum and peri-implant bone, and faster healing of soft tissue ${ }^{(14)}$.Tsoukaki et al ${ }^{(15)}$ reported that the inflammation occurring during the first 3 weeks of healing played a crucial role in 
early peri-implant bone loss which can be prevented or minimized if soft tissue wound around the dental implants heals quickly with little inflammation and scar tissue formation.

The results of this study show that the amount of crestal bone loss from baseline to the sixth month was less in the flapless group than the flap group. This difference was statistically significant. The results of the current study appear to coincide with the findings of other investigators ${ }^{(16)}$, as the cases treated with the flapless technique have shown significantly less bone loss compared with the cases treated with a conventional flap technique. The higher bone loss rate occurred with widely mobilized surgical flap because the interdental bone in the proximity to the implant is denuded from the periosteum thus affecting the nutrition of the bone and papillae, giving rise to unpredictable degree of resorption of the interproximal marginal bone. Shamsan et al ${ }^{(17)}$ reported a mean crestal bone loss of $0.45 \pm 0.22 \mathrm{~mm}$ in the flapless technique and $0.82 \pm 0.09 \mathrm{~mm}$ in the conventional flap group. Divakar et al ${ }^{(18)}$ concluded that flapless implant surgery results in lesser loss of marginal bone and results in better patient comfort when compared with the flap technique, provided that proper patient selection is essential for carrying out flapless implant surgery.

On the other hand, Cannizzaro et al ${ }^{(19)}$ reported that peri-implant crestal bone loss in both flap and flapless techniques had no statistically significant differences at baseline and 1 year after loaded. Becker et al ${ }^{(20)}$ also noted non-significant bone loss around implants placed with flapless technique until 2 years. Jeong et al ${ }^{(21)}$ observed mean marginal bone loss ranging from 0.0 to $1.1 \mathrm{~mm}$ with flapless technique over a period of 1 year.

In this study, non-significant difference was found in bone density between both groups as bone density was increased in the flapless group as well as in the flap group. The increased bone density, in both groups, could be attributed to the increase in cancellous bone remodeling. After implant placement, there were changes in the rate of cancellous bone remodeling associated with changes in the blood supply that can also affect the bone remodeling rate. The increase in blood supply due to angiogenesis or arteriogenesis may explain the changes that occurred in cancellous turnover ${ }^{(22)}$. The results of the present study are in accordance with Shamsan et al (17) who found no statistically significant difference between the flapless and flap groups regarding the mean bone density.

\section{CONCLUSION}

In conclusion, both techniques achieved good success rates, and the flapless technique showed no advantage over flap technique regarding probing depth, implant stability and bone density. Moreover, the use of flapless technique might produce less postoperative soft tissue inflammation, pain and significant reduction in the amount of crestal bone loss compared to flap technique.

\section{REFERENCES}

1. Veis A, Parissis N, TsirlisA, Papadeli C, Marinis G, Zogakis A, et al. Evaluation of peri-implant marginal bone loss using modified abutment connections at various crestal level placements. Int J Periodontol Restorative Dent . 2010; 30: 609- 17.

2. Abrahamsson I, Berglundh T. Effects of different implant surfaces and designs on marginal bone-level alterations. Clin Oral Implants Res 2009; 20: 207- 15.

3. Cochran D, Bosshardt D, Grize L. Bone response to loaded implants with non-matching implant-abutment diameters in the canine mandible. J Periodontol 2009; 80: 609- 17.

4. Cappiello M, Luongo R, DiIorio D. Evaluation of periimplant bone loss around platform-switched implants. Int J Periodontics Restorative Dent 2008; 28: 347- 55.

5. Annibali S, Ripari M, Monaca G, Tonoli F, Cristalli MP. Local complications in dental implant surgery: prevention and treatment. Oral Implantol 2008; 1: 21- 33.

6. Worthington P, Bolender CL, Taylor TD. The Swedish system of osseointegrated implants: problems and complications encountered during a 4- year trial period. Int J Oral Maxillof Implants 1987; 2: 77- 84. 
7. Mombelli A, Lang NP.Clinical parameters for the evaluation of dental implants.Periodontol 2000;4: 81-6.

8. Wang F, Huang W, Zhang Z, Wang H, Monje A, Wu Y. Minimally invasive flapless vs. flapped approach for single implant placement: A 2-year randomized controlled clinicaltrial. Clin.OralImpl.Res 2017; 28: 757- 64.

9. Jiao G, Gao M. Clinical observation on the effect of minimally invasive flapless technique and implant prognosis in oral implants, Int J Clin Exp Med 2018;11: 165- 72.

10. Anumala D, Haritha M, Sailaja S, Prasuna E, Sravanthi G, Reddy NR, et al. Effect of Flap and Flapless Implant Surgical Techniques on Soft and Hard Tissue Profile in Single- Stage Dental Implants. JOro fac Sci 2019;11:11-5.

11. Mall N, Dhanasekar B, Aparna IN. Validation of implant stability: A measure of implant permanence. Indian J Dent Res. 2011;22: 462- 7.

12. Atsumi M, Park S, Wang H. Methods Used to Assess Implant Stability:Current Status. Int J Oral Maxillofac Implants 2007; 22: 743- 54.

13. CannizzaroG, Leone M, Consolo U, Ferri V, EspositoM. Immediate functional loading of implants placed with flapless surgery versus conventional implants in partially edentulous patients: a 3-year randomized controlled clinical trial.Int J Oral Maxillofac Implants 2008; 23:867-75.

14. Kim J, Choi B, Li J, Xuan F, Jeong M. Blood vessels of the peri-implant mucosa: a comparison between flap and flapless procedures. Oral Surg Oral Med Oral Pathol Oral RadiolEndod2009; 107: 508-12.

15. Tsoukaki M, Kalpidis CD, Sakellari D, Tsalikis L, Mikrogiorgis G, Konstantinidis A, et al. Clinical, radiographic, microbiological, and immunological outcomes of flapped vs. flapless dental implants: a prospective randomized controlled clinical trial. Clin Oral Implants Res 2013; 24: 969-76.
16. Nickenig HJ, Wichmann M, Schlegel KA, Nkenke E, Eitner S. Radiographic evaluation of marginal bone levels during healing period, adjacent to parallel-screw cylinder implants inserted in the posterior zone of the jaws, placed with flapless surgery. Clin Oral Implants Res 2010; 21 : 1386-93.

17. Shamsan Y, Eldibany R, El Halawani G, Fahmy R. Flapless Versus Conventional Flap Approch For Dental Implant Placement In The Maxillary Esthetic Zone. Alex Dent J 2018; 43:80-5.

18. Divakar TK, Arularasan SG, Baskaran M, Packiaraj I, Kumar ND.Clinical Evaluation of Placement of Implant by Flapless Technique over Conventional Flap Technique. JMaxillofac Oral Surg 2020; 19:74-84.

19. Cannizzaro G, Felice P, Leone M, Checchi V, Esposito M. Flapless versus open flap implant surgery in partially edentulous patients subjected to immediate loading: 1-year results from a split-mouth randomised controlled trial. Eur J Oral Implantol 2011; 4:177- 88.

20. Becker W, Goldstein M, Becker BE, Sennerby L. Minimally invasive flapless implant surgery: a prospective multicenter study. Clin Implant Dent Relat Res 2005; 7:21-27.

21. Jeong SM, Choi BH, Kim J, Xuan F, Lee DH, Mo DY et al.1-year prospective clinical study of soft tissue conditions and marginal bone changes around dental implants after flapless implant surgery. Oral Surg Oral Med Oral Pathol Oral RadiolEndod 2011; 111:41- 6.

22. Celenk C, Celenk P. Evaluation by quantitative magnetic resonance imaging of trabecular bone quality in the dentate and edentulous mandible. Clin.Oral Implants Res 2008; 19: 15- 18 . 